\title{
OUTDOOR LightiNG WiND GENERATORS WITH BASALT FIBER COMPOSITE BLADES
}

\author{
Merab SHVANGIRADZE ${ }^{1}$ \\ ${ }^{1}$ Department of Industrial and Technological Machinery and Mechatronics, Faculty of Transportation and Mechanical \\ Engineering, Georgian Technical University, 77, Merab Kostava str., Tbilisi, Georgia
}

shvango@gmail.com

DOI: $10.31490 /$ tces-2018-0017

\begin{abstract}
Small wind generators are successfully applied for outdoor lighting on highways, parks, seaside boulevards. We developed technologies that gives an opportunity to manufacture wind rotor, the main element of this type of generators, using basalt fiber composite, and to manufacture generator itself. Based on the research data we manufactured $200 \mathrm{w}$ capacity wind generator equipped with basalt fiber composite blades.
\end{abstract}

\section{Keywords}

Outdoor lighting, Wind turbines, Basalt fiber, Polymer composite

\section{Introduction}

The use of small wind generators as a source of power for outdoor lighting in seaside boulevards and highways is ecologically efficient and has substantial economic effect. In both cases, we need hundreds of kilometers of underground or air electrical cables and wires, which is related to significant costs. Since the highways and the seashores are mainly wide, open spaces, the movement of active wind currents occurs there systematically. Therefore, in such places the use of small wind generators for outdoor lighting is efficient in every way.

The wind rotor is an important part of the wind generator that accumulates wind energy, turns it into a mechanical energy on his axis as materialized rotating moment. The use of rotating moment given on the shaft to start an electric generator is a usual task of mechanical engineering the solution of which is not connected with special difficulties.

The polymer composite materials are used in wind rotors' blades manufacturing, the main components of which are fiber materials. Mainly glass and carbon fibers are used. Recently, the basalt fiber is of great interest, that is manufactured in Georgia as well (Rustavi, factory "BASALT FIBER"). Based on the above we created manufacturing technology for wind generator blades and rotors with basalt fiber composites.

\section{Basic Part}

It should be noted that the product manufacturing technology from the polymer composite materials is principally distinguished from traditional technologies, where the product is first produced from the necessary material and then the relevant detail is cut out from the given product. In case of the polymer composites product manufacturing and production of the material runs simultaneously. This condition requires the creation of appropriate technological process for each particular product from polymer composite material and at the same time requires creation of appropriate appliance. Therefore, the role of mechanical engineering in manufacturing polymer composite products is significantly important.

To make the rotor blades we have created moldshapes from wood and metal. The blades of the wind generators are mainly made of two, front and back surfaces, for that, for each individual size blade, we prepare two mold-shapes for the front and rear surfaces. In the mold-shape, we insert fitted to template and size, basalt fiber woven material so that each layer is saturated with a polyester solution. The initiator methyl ethyl ketone peroxide and the accelerator cobalt naphthenate are added to polyperfire $0,1-0,15 \%$ [1]. After polymerization and strengthening, the front and rear surfaces of the blades are attached to longitudinal direction. This creates hollow shaped, hollow-bodied high-strength and light- weight blades which is crucial in wind energetics. As for the outdoor lighting electrical generator rotor blades, they can be manufactured as the single monolithic product, without two-parted hollow- 
bodied. Therefore we use only one mold-shape, for rear surface (Picture 1). It has following parameters: length $\mathrm{L}=1900 \mathrm{~mm}$; width $\mathrm{B}=250 \mathrm{~mm}$. The outdoor lighting electrical generator rotor blade length varies between 700 and $1500 \mathrm{~mm}$. These parameters depend on environmental conditions, in particular, speed of the wind and air density. Based on the demand, the moldshape that we created gives a possibility to manufacture different sizes of blades and rotor for each specific case. We carve the template according to the blade size, which is determined to get the layers of the basalt fibers woven material in the form of blade formation (Fig.2).

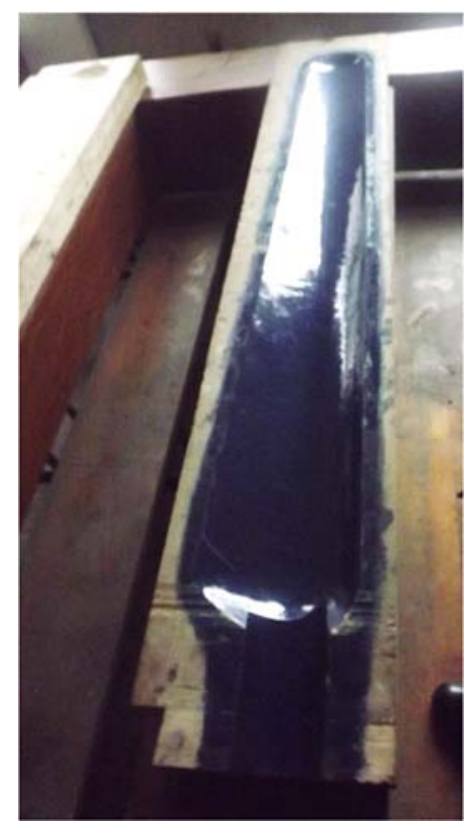

Fig.1 Polymer composite blade mold-shape

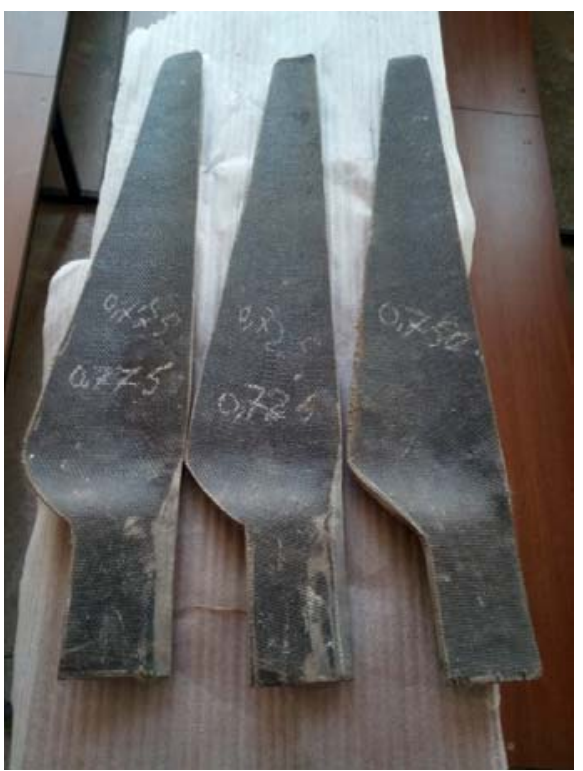

Fig. 2 Basalt composite blade products $L=700 \mathrm{~mm}, B=150 \mathrm{~mm}, b=35 \mathrm{~mm}$

When manufacturing a blade it is extremely important to optimize the number of layers of basalt woven material. By increasing their numbers increases the strength of the blade and at the same time increases its mass and cost. Therefore, based on research, the method of determining the optimal number of layers should be formed.

The wind causes bending deformation on rotor blades. Our task is to define the load of wind on blades and bending moments, and also test basalt fiber multilayer samples on bending strength. By using these data, we can determine the number of woven layers of basalt fiber for the blade manufacturing.

Based on testing of wind rotors in the aerodynamic tunel, the empirical formula of the forces caused by wind flows is obtained $[2,3]$ :

$$
F=C_{y} S \frac{\rho}{2}\left(\omega^{2} r_{m}^{2}+v^{2}\right)[\mathrm{Kg}]
$$

where: $C_{y}-$ Coefficient of lifting force

$$
\begin{aligned}
& S-\text { Blade surface area, } \mathrm{m}^{2} ; \\
& \rho-\text { Air density, } \mathrm{kg} \cdot \mathrm{sec}^{2} / \mathrm{m}^{4} ; \\
& \omega-\text { Angular speed of rotor turn, } \mathrm{rad} / \mathrm{sec} \\
& r_{m}^{2}-\text { Conditional rotor radius } \\
& v-\text { Wind speed, } \mathrm{m} / \mathrm{sec} .
\end{aligned}
$$

Some values of this formula are calculated separately, based on initial data. angular speed of rotor turn is defined by the following formula $\omega=Z \times v / R \mathrm{rad} / \mathrm{sec}$, where $Z$ - The coefficient of high speed, that for the three-blade rotor equals $4,7-5, R$ is Rotor radius, $m$. the rotor's conditional radius is determined by the figure $r_{m}^{2}=\left(R^{2}+R r_{o}+r_{0}^{2}\right) / 3$, where $r_{o}$ initial radius (blade tip).

As we already noted, when developing blade manufacturing technology, depending on the required strength, parameters must be determined. In this case, basalt fiber woven layer quantity in composite material. The bending strength of the blade, in connection, is the weakest point. Once we calculate with the above formulas the forces that are acting on blades then we have to define bending stress from the given forces. For this we can compare blade shape to trapezoid, consequently the center of gravity of the trapezoid should be considered as a coordinate of the point of total force acting on it.

The distance from the bottom, base of the trapezoid to the center of the gravity is defined by the formula [4], $h=l(B+2 b) / 3(B+b)$. The use of $h$ as a bending moment allows us to define its value in the dangerous part - at the connection of the blade. The calculation of wind impact forces and bending moments for different wind values were carried out through the formulas provided. (Fig.3,4). The calculations have been made for the two different sized blades shown on Fig. 2.

To test the mechanical properties of the polymer composite material obtained from rainforsing basalt fibers, we prepared samples that were tested for bending strength. [5, 6, 7]. The samples have two permanent parameters - length $-250 \mathrm{~mm}$ and width $-45.5 \mathrm{~mm}$. The number of basalt woven layers is $20,40,60$ and 80 . The 
results of the samples tests are given in column bar graphs on Fig 5. For clarity sake we recalculated the ultimate bending moment values for $1 \mathrm{dm}$ width product.

As it is showed on Fig. 5 the ultimate bending strength values do not change with the quantity or the layers. Consequently, there is a need to conduct comparative analysis and find the pattern corresponding coefficient in order to determine empirical correlation between them. However, with sufficient accuracy for practical calculations with graphical data we can determine conditions in which we get blades with the required strength.

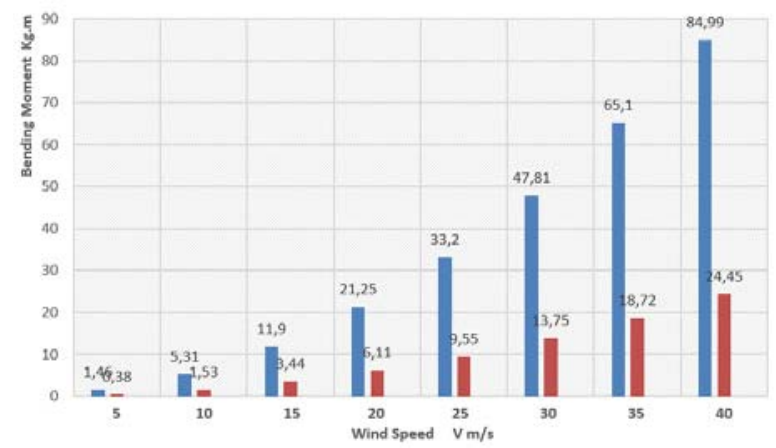

Fig. 3. Forces acting on the rotor blades.

The parameters of blades: $\mathrm{L}=700 \mathrm{~mm}, \mathrm{~B}=150 \mathrm{~mm}, \mathrm{~b}=35 \mathrm{~mm}$. and $\mathrm{L}$ $=1200 \mathrm{~mm}, \mathrm{~B}=185 \mathrm{~mm}, \mathrm{~b}=70 \mathrm{~mm}$

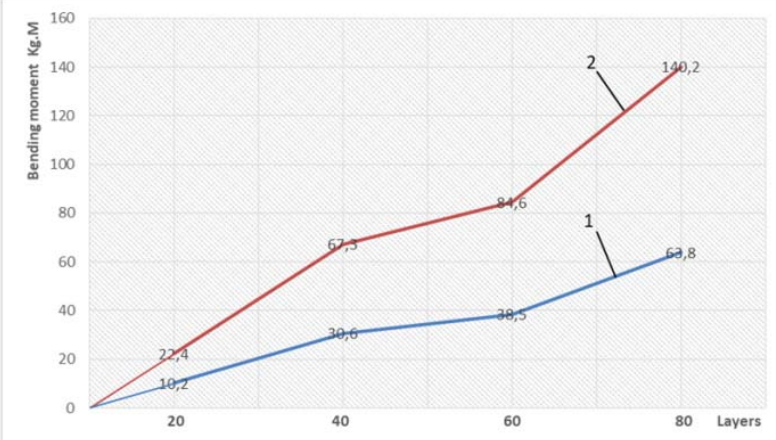

Fig. 5. The ultimate bending strength of basalt composite:

1 the parameters of sample are length $-250 \mathrm{~mm}$, width $-45.5 \mathrm{~mm}$;

2. recalculated for the product with values for $100 \mathrm{~mm}$.

We manufactured polymer composite blades of wind rotors for outdoor lighting the template of which is presented on Fig. 2. The values of bending moment by wind force impact gradually decreases from connection to tip. For this reason, quantity of basalt woven layers is less at the tip of the blade. We divided the given blade into three section in longitude direction in which the number of layers from connection changes and are: 10, 7 and 4 . With the received graphs, we have to define what is the bending strength of the given blade, when the width in connection is $95-100 \mathrm{~mm}$. The study of the values presented on the graph 2 shown on Fig. 5 gives an opportunity to define that ultimate bending momentum of the blade is $13,5 \mathrm{~kg} . \mathrm{m}$. Therefore, as we can define from the graph on Fig. 4 given rotor works $30 \mathrm{~m} / \mathrm{sec}$ wind speed environment. For the blade working in the same environment with parameters $\mathrm{L}=1200 \mathrm{~mm}, \mathrm{~B}=185 \mathrm{~mm}$, $\mathrm{b}=70 \mathrm{~mm}$, bending moment is $47-48 \mathrm{kgm}$. Therefore, in case of $150 \mathrm{~mm}$ connection width, maximum number of basalt woven material layers, proportional calculation should equel 20 , which corresponds to $10 \mathrm{~mm}$.

Using given blades of basalt fiber composites we manufactured 200 watts capacity small wind generators for outdoor lighting (Fig. 6). These generators are successfully applied on highways, seaside boulevards and for outdoor lighting in parks (Fig. 7).

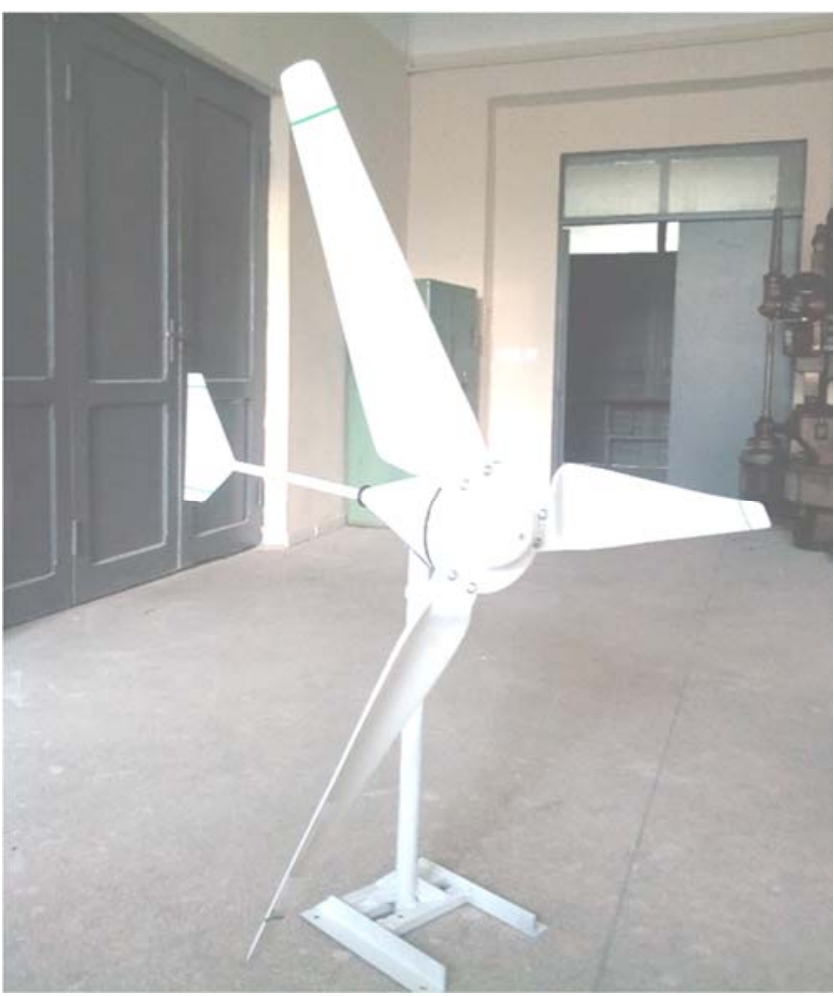

Fig. 6 Wind generator with basalt composite blades, 200 wt capacity

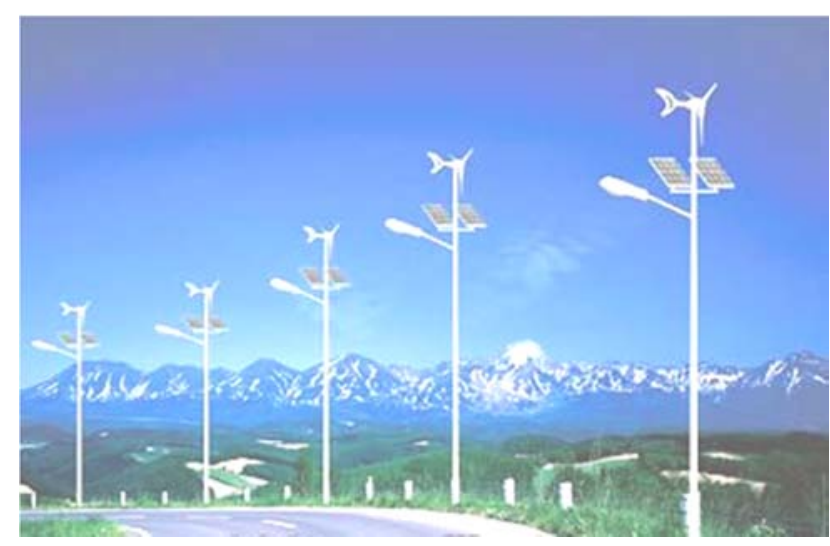

Fig. 7 Outdoor lighting wind generators on highways

\section{Conclusion}

Our studies show that the conditions in Georgia are absolutely realistic for applying small wind generators as a source of outdoor lighting on highways, and seaside boulevards. The fact that basalt fibers and basalt fibers woven materials are produced in Georgia, makes production of wind generators not only ecologicaly 
efficient but is also justified in economic terms. Based on research, we have established grounds for optimizing parameters of wind generators, as well as the basic aspects of their manufacturing technological processes.

Naturally, manufacturing based on local raw materials and labour, always gives a high economic effect. Using the basalt fibers woven from the polymer composite materials we will manufacture rotor blades and electric generator protective lids. The manufacturing of the remaining parts of the wind generators is not is not difficult as well. Only electric generators working on constant magnets with a low rotation number has to be purchased.

The research and experiments performed in GTU transportation and mechanical engineering faculty gives a base to manufacture wind electric generators for outdoor lighting, on highways, and seaside boulevards. This will be a good example in terms of stimulating the local industry.

\section{References}

[1] LUBIN, J. Hand book in composite materials. Mashinostroenie. 1988, vol 1, Moscow. ISBN 5217-00225-5.

[2] SHEFTER Y. I. User of wind energy. M. Mashinostroenie, 1998.

[3] KAPANADZE, Sh. Wind micro and small power plants. Tbilisi 2001.

[4] BRONSHTEIN, I. N. and K. A. SEMENDYAEV. Hand book of Mathematics. Toinbner Leipzig, Science Moscow. 1981.

[5] TIMOSHENKO, S. P. Strength of materials. Mashinostroenie. 2003, vol 1.

[6] SHVANGIRADZE, M., T. GERKEULI and D. BUCCKRIKIDZE. Strength test of a basalt fiber composite. Proceedings of the Georgian Technical University. 2016, vol.2, no. 500.

[7] LEE J.H, RHEE K.Y, PARK S.J. The tensile and thermal properties of modified CNT reinforced basalt/epoxy composites. Mat Sci Eng A Struct 2010;527(26) 6838e43

\footnotetext{
About Authors

Merab SHVANGIRADZEE was born in Tbilisi, Georgia. He received his M.Sc. from Mechanical Engineering in 1981. His research interests include Cutting in a hot state of stainless and heat-resistant steels and alloys; Production of high pressure bottles from composite materials of basalt fibers; Technologies for making wind rotors using the polymer composite materials; Wind Generators Production Technologies.
} 